
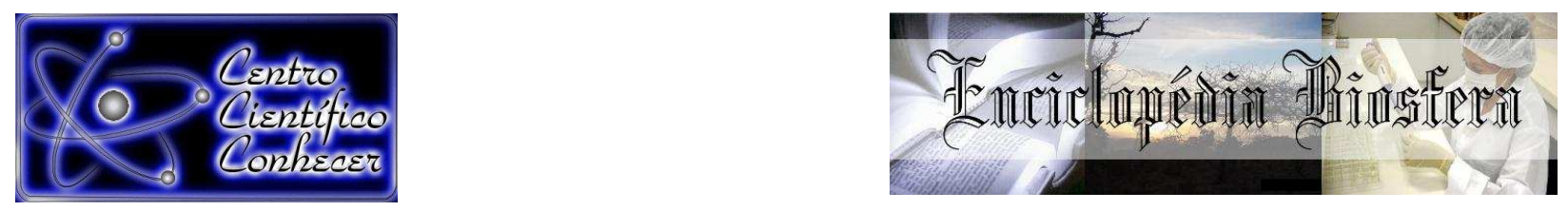

\title{
EVOLUÇÃO DO EFETIVO DE BOVINOS NO BRASIL, ESTADO DE GOIÁS E MUNICÍPIO DE JATAÍ (GO)
}

\author{
Vinicio Araujo Nascimento ${ }^{1}$, Márcio Borrás Batista Filho², Marcia Dias ${ }^{3}$ \\ ${ }^{1}$ Professor Doutor do Curso de Zootecnia-UFG/Regional Jataí, Jataí-GO, e do curso \\ de Medicina Veterinária-UNIFIMES, Mineiros-GO, Brasil (e-mail: \\ vinicioaraujon@yahoo.com.br). \\ ${ }^{2}$ Graduando do Curso de Zootecnia, UFG/Regional Jataí, Jataí-GO, Brasil. \\ ${ }^{3}$ Profa. Doutora do Curso de Zootecnia-UFG/Regional Jataí, Jataí-GO, Brasil.
}

Recebido em: 08/04/2016 - Aprovado em: 30/05/2016 - Publicado em: 20/06/2016 DOI: 10.18677/Enciclopedia_Biosfera_2016_054

\begin{abstract}
RESUMO
Ao trabalhar com a cultura bovina, é importante saber de sua evolução. A bovinocultura brasileira precisa ser conhecida pelo histórico em dados de sua produção. Assim, objetivou-se realizar o estudo da evolução e distribuição dos bovinos no Brasil, Centro-Oeste, Goiás e município de Jataí-GO. O efetivo bovino brasileiro evoluiu 691\% de 1912 a 2014 colocando o Brasil em patamar privilegiado quando comparado a outros países, sendo superado apenas para efetivo bovino da Índia. O crescimento do rebanho brasileiro está ligado a introdução do grupo genético Bos taurus taurus indicus, os zebuínos, além de avanços significativos na nutrição animal e melhoramento genético. O Centro-Oeste destacou-se frente às outras regiões, devido ao crescente aumento do efetivo bovino, sobretudo no Mato Grosso. O deslocamento do rebanho para terras mais baratas ainda se mostra presente, fato que aconteceu na microrregião do Sudoeste de Goiás, em municípios como Rio Verde e Jataí - GO. Pela competitividade, a pecuária perde espaço para outras culturas, como a de soja e a de milho. Tal situação exerce a pressão sobre a atividade, em contrapartida contribui para o avanço, o que resulta em melhor eficiência produtiva e o desenvolvimento conjunto de estratégias tecnológicas relacionadas a nutrição, reprodução e sanidade.
\end{abstract}

PALAVRAS-CHAVE: bovinocultura, distribuição regional, produção

\section{THE CATTLE EFFECTIVE DEVELOPMENT IN BRAZIL, GOIAS STATE AND CITY JATAÍ (GO)}

\section{ABSTRACT}

When working with the cattle farm, it is important to know its evolution. The Brazilian cattle farm needs to be known by the historical data of production. Thus, the objective was to conduct the study of the evolution and distribution of cattle in Brazil, Central West, Goiás and the city of Jataí-GO. Effective Brazilian cattle evolved $691 \%$ from 1912 to 2014 putting Brazil in a privileged level compared to other countries, surpassed only effective bovine India. The growth of the Brazilian herd is on the introduction of genetic group Bos taurus indicus, the zebu, as well as significant advances in animal nutrition and breeding. The Midwest stood out against other regions due to increasing bovine effective, especially in Mato Grosso. The herd shift to cheaper land still shows this fact has happened in the micro region of the 
Southwest of Goiás, in cities like Rio Verde and Jataí - GO. For competitiveness, livestock loses ground to other crops, such as soybeans and corn. This situation exerts pressure on activity, on the other hand contributes to the advance, resulting in improved production efficiency and the joint development of technological strategies related to nutrition, reproduction and health.

KEYWORDS: cattle farm, regional distribution, production

\section{INTRODUÇAO}

A bovinocultura brasileira tem grande importância no contexto mundial, visto a capacidade produtiva e a eficiência na superação dos obstáculos nacionais e globais, como a crise política e econômica interna e, também, a crise mundial. Desde 2004, o Brasil ostenta a posição de maior exportador mundial de carne bovina, caracterizando como maior rebanho comercial do mundo, e destinando $80 \%$ da produção para o abastecimento do mercado interno, com um consumo médio de 39,2 kg por habitante (ABIEC, 2014).

Com um efetivo de aproximadamente 212 milhões de bovinos em 2014 e a área de pastagens de 167 milhões de hectares, o Brasil produz a carne com menor custo, caracterizando o país com o mercado mais competitivo (IBGE, 2014). Em termos de bovinos confinados, há dados recentes demonstrando que são terminados cerca de 4,66 milhões de cabeças, cerca de $11 \%$ do total de abate. Pode-se observar que o bovino brasileiro é terminado praticamente a pasto favorecendo a produção de carne competitiva mundialmente. Enquanto ainda, a taxa de desfrute brasileira, que mede a capacidade do rebanho em gerar excedente, é de $20,11 \%$, sendo inferior às taxas de desfrute de países desenvolvidos (ABIEC, 2014). Isso evidencia a necessidade de avanços técnicos produtivos no setor, demonstrando o quanto este setor é promissor e como fonte de renda segura.

O agronegócio brasileiro gera 33,5 milhões de empregos. A pecuária de corte é responsável por sete milhões e um emprego direto gera três indiretos. Isso demonstra sua importância na economia brasileira. Para maior destaque, foi observado que com o abate total de 42,8 milhões de cabeças no ano de 2010, houve o movimento de cerca de 167,5 bilhões de reais, representando aproximadamente 8\% do PIB brasileiro (SCOT, 2011).

A cada cinco $\mathrm{kg}$ de carne comercializada no mundo um $\mathrm{kg}$ é brasileiro e a pecuária de corte está presente em $75 \%$ das propriedades agrícolas brasileiras (IBGE, 2014). Os bovinos Bos taurus indicus sem dúvida foram o avanço para pecuária brasileira, sobretudo associados à difusão de conhecimentos em relação à nutrição animal e ao melhoramento genético. Isto em conjunto elevou o rendimento médio de carcaça, sendo entre 52,3 a 55\% (ABIEC, 2014).

O investimento em tecnologia e capacitação profissional, vem sendo cada vez mais empregado nas propriedades rurais. Também, o desenvolvimento de políticas públicas contribui efetivamente para evolução da bovinocultura. Tal efeito pode ser observado a partir da exigência da rastreabilidade dos animais, do nascimento ao abate, e do maior controle da sanidade animal, principalmente com o programa de controle e erradicação da brucelose, tuberculose e febre aftosa. Assim, o Brasil ganhou destaque por atender as exigências dos mercados rigorosos e conquistou espaço no cenário mundial.

As técnicas específicas a cada sistema de produção vêm impulsionando os índices de produtividade dos animais e colaborando para a pecuária ser cada dia mais eficiente e sustentável, conseguindo produzir com maior eficiência e mantendo $68 \%$ da área do território em florestas preservadas (ABIEC, 2011). 
Assim, objetivou-se realizar o estudo da evolução e distribuição dos bovinos no Brasil, no Centro-Oeste, em Goiás e no município de Jataí-GO.

\section{MATERIAL E MÉTODOS}

O método utilizado foi o de levantamento de dados secundários. Com o método descritivo pretendeu-se descrever as características de uma realidade como se apresenta. Foi realizada a pesquisa exploratória com abordagem qualitativa de levantamentos bibliográficos acerca da temática evolução da bovinocultura complementados por pesquisa exploratória no Brasil, no Centro-Oeste, em Goiás e no município de Jataí-GO.

A pesquisa se pautou em estudo bibliográfico e documental, a partir de informações coletadas por pesquisas em relatórios, banco de dados estatísticos, artigos, livros, internet e publicações de índices de estudos catalogados sobre a temática nos estudos extraídos de órgãos oficiais, empresas públicas e privadas: a) Dados do Censo Agropecuário do Instituto Brasileiro de Geografia e Estatística (IBGE). b) Dados do Anuário da Pecuária Brasileira.

Os dados do efetivo bovino foram retirados do banco de dados SIDRA (IBGE, 2014). As análises foram realizadas a partir da visualização dos dados em gráficos, visto melhor interpretação evolutiva.

\section{RESULTADOS E DISCUSSÃO A EVOLUÇÃO DO EFETIVO BOVINO NO BRASIL}

Os primeiros bovinos chegaram no Brasil, em 1533, na Expedição de Martin Afonso de Souza, donatário da primeira Capitania Portuguesa na llha de São Vicente (SILVA et al., 2012). A seguir, houve a expansão principalmente para o sul do país pelos missionários passando por Paraná, Santa Catarina até chegar no Rio Grande do Sul. Em 1550, Tomé de Sousa trouxe bovinos de Cabo Verde, havendo a difusão para a região Nordeste (MALDONADO, 1917 citado por PEIXOTO, 2010a).

As primeiras raças trazidas para o Brasil foram importadas da Espanha e Portugal, sendo os bovinos: Minhota, Mirandesa, Alentejana, Arouquesa e Transtagana. Estas raças sofreram seleção natural com o tempo, visto que o clima, a disponibilidade de alimento, as enfermidades com ecto e endo parasitas, além dos critérios de seleção estabelecidos pelo homem na época específica, formaram as raças nativas brasileiras, como os bovinos das raças Caracu, Crioula, Junqueira, Curraleiro, China, Franqueiro, Mocho Nacional, Sertaneja, além de outras de menor importância (PEIXOTO, 2010b; SILVA et al., 2012).

Com o crescimento da economia na região litorânea, com o aumento populacional e, consequentemente, a ocupação do interior do país, a criação de gado foi se deslocando. Assim, a criação de bovinos foi sendo implantada nas diversas localidades do país. A busca por minérios e a captura de índios foram importantes no processo de disseminação dos rebanhos bovinos. Portanto, a atividade pecuária só teve relevância com o declínio da indústria mineradora no século XVIII, visto que até então a bovinocultura era uma economia secundária. Também, a tendência da época era a produção de açúcar na região litorânea (SILVA et al., 2012).

A extração de recursos naturais do solo pelo cultivo de lavoura sem a tecnologia apropriada para reposição de nutrientes foi determinante para a expansão da pecuária em solos com baixa fertilidade (ARAÚJO et al., 2009; MEZZADRI, 2014). Sabe-se que quando não se repõem os nutrientes, o solo fica impróprio para as culturas exigentes de maior fertilidade. Então, o solo degradado, fraco e pouco ENCICLOPÉDIA BIOSFERA, Centro Científico Conhecer - Goiânia, v. 13 n.23; p. 612 2016 
produtivo para o cultivo das culturas tropicais (café, cana de açúcar, milho, etc.), transformavam-se em propriedades pecuárias, devido as pastagens serem de menor exigência em relação à qualidade do solo (MONZATTO et al., 2002).

Os zebuínos oriundos da Índia tiveram a entrada no país iniciado por D. Pedro I, em 1826, na Fazenda Real de Santa Cruz, estado do Rio de Janeiro (SANTIAGO, 1975), mas sem nenhum interesse produtivo. Em 1870, ocorreu a crise do café nas lavouras paulistas e fluminenses, acelerando a atividade pecuária. Também, já existiam grandes centros comerciais urbanos. Os animais que predominavam naquele momento eram os bovinos da raça Caracu e Holandês (CRPBZ, 2015a).

A importação do gado zebu pode ser dividida em cinco fases. A primeira foi entre os anos de 1813 e 1870, na qual houve um casal de animais vindo da Costa do Malabar, região mais úmida da Índia meridional, e foi deixado no porto de Salvador. Nesse período, vários exemplares da espécie chegaram ao Brasil vindo da Índia e do Paquistão, e os bovinos da raça Guzerá tornaram-se predominante no processo introdutório (CRPBZ, 2015b).

A segunda fase ocorreu entre os anos de 1875 a 1891 e correspondeu ao período em que os pecuaristas perceberam a viabilidade econômica dos bovinos zebuínos. Foram trazidos da Índia alguns reprodutores criteriosamente selecionados por produtores brasileiros, entre os quais o criador Manuel Hubelhart Lemgruber. Essa fase caracterizou-se pela chegada de bovinos da raça Nelore, o que veio a possibilitar a diversificação posterior da espécie no país (CRPBZ, 2015c).

A terceira fase foi determinada entre os anos de 1898 a 1921. Neste período, lotes de até 100 ou mais animais foram desembarcadas no país, com destaque para os criadores do Triângulo Mineiro, região que se tornou a maior referência na criação do Zebu. O produtor Teófilo de Godoy foi o pioneiro a ir a Índia com a finalidade de escolher os zebuínos (CRPBZ, 2015d).

A quarta fase foi entre os anos de 1930 a 1960, sendo sucessiva ao ano de 1921, quando o governo federal proibiu a importação de zebuínos da Índia. Assim, a quarta fase foi sequencial ao tempo em que o crescimento do rebanho zebuíno estava interrompido. Manoel de Oliveira Prata e Ravísio Lemos conseguiram licença para obter um lote de quase 200 animais, com a exigência de que os mesmos permanecessem por cerca de 3 meses em quarentena na Ilha do Governador. Em 1960, chegou ao Brasil o touro Karvadi, tido como o "pai" da linhagem Nelore brasileira. Este touro foi trazido pelo veterinário José Deutsch e José Dico, a serviço do pecuarista Torres Homem Rodrigues da Cunha (CRPBZ, 2015e). Neste período, houve a II Guerra Mundial (1939 a 1945), proporcionando a expansão da bovinocultura brasileira, visto que a Europa precisava importar carne e o Brasil era um produtor de carne barata produzida a pasto. Assim, grandes indústrias frigoríficas mundiais, como a Swift e a Anglo, se instalaram no país. A raça Nelore, nestes anos, começou a se destacar pela resistência e produtividade em relação às variadas raças já existentes (CRPBZ, 2015e).

A quinta fase é a mais recente, determinada entre os anos de 1994 a 2010. Neste período, ocorreu a chegada da raça Brahman e muitos entraves políticos para a liberação da importação de genética direto da Índia. No ano de 2005, um grupo de pecuaristas, liderado por Jonas Barcellos Corrêa Filho, conseguiu a liberação definitiva para importação de embriões e, no ano de 2009, chegaram ao Brasil 350 embriões (CRPBZ, 2015f).

A pecuária bovina brasileira é desenvolvida em todos os estados da união e a partir dos dados de pesquisas do IBGE pode-se conhecer a evolução do efetivo de rebanho bovino do país desde o ano de 1912, data em que se encontrava cerca de ENCICLOPÉDIA BIOSFERA, Centro Científico Conhecer - Goiânia, v.13 n.23; p. 613 2016 
30.705.000 milhões de bovinos. No ano de 2014, os registros do efetivo foram de 212.343.932 milhões de cabeças, representando o crescimento médio de 1.781 .773 milhões de cabeças por ano (Figura 1).

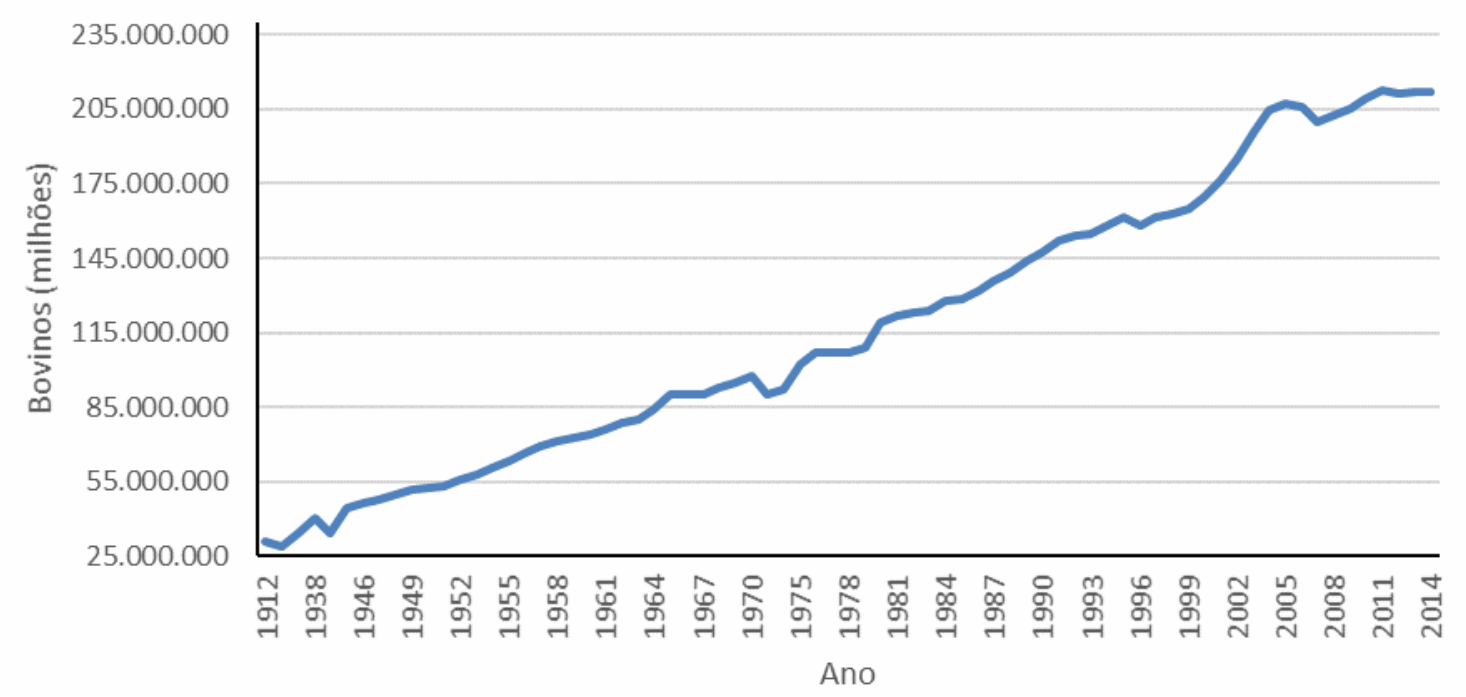

FIGURA 1. Evolução do efetivo bovino no Brasil. Fonte: Adaptado IBGE (2014).

A EVOLUÇAO DO EFETIVO BOVINO NAS GRANDES REGIÕES DO BRASIL

A bovinocultura é encontrada em todas as grandes regiões brasileiras (Figura 2) e nos diferentes biomas, o que permite a criação de diferentes raças no país. Nas regiões Sudeste, Centro-Oeste, Norte e Nordeste com os biomas Amazônia, Cerrado, Caatinga, Pantanal e Mata Atlântica, prevalece a criação de bovinos Bos taurus indicus, com amplo destaque para a raça Nelore. Na região Sul, com os biomas Pampa e Mata Atlântica, prevalece a criação de bovinos Bos taurus taurus, com ênfase nas raças Hereford, Angus, Simental e Charolês (EUCLIDES-FILHO \& EUCLIDES, 2010).

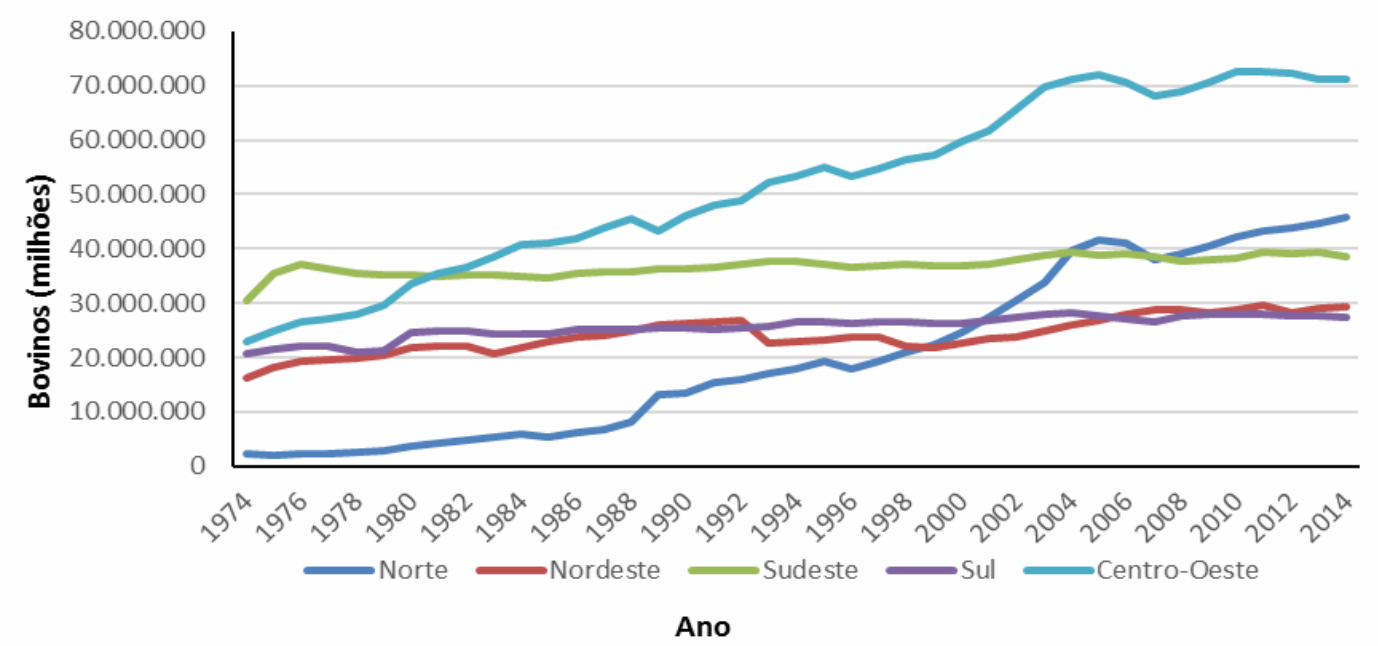

FIGURA 2. Evolução do efetivo bovino nas grandes regiões do Brasil. Fonte: Adaptado IBGE (2014).

A pecuária bovina brasileira caracteriza-se pela criação de bovinos a pasto, 0 que faz com que o Brasil tenha os menores custos de produção de carne do mundo (CARVALHO et al., 2009). Em 1950, foram desenvolvidos estudos preliminares sobre o uso racional de pastagens, pela Escola Superior de Agricultura Luiz de Queiroz - ESALQ, os quais possibilitaram avanços na nutrição animal a partir de 
forragens (PEIXOTO, 2010a). Assim, o desenvolvimento tecnológico nos centros de pesquisas e nas universidades sobre espécies forrageiras caracterizam 0 desenvolvimento evolutivo na nutrição animal e na produtividade dos bovinos. Logo, a entrada de raças zebuínas com melhor valor genético no país contribuiu para que a expansão da atividade no Brasil central fosse possível.

Entre 1975 e 2006, as áreas de pastagens do país diminuíram nas regiões Sudeste, Sul e Centro-Oeste, em cerca de 32,2, 14,0 e de 7,3\%, respectivamente. Houve aumento nas regiões Norte de $518 \%$ e Nordeste de 6,6\%. No Brasil, como um todo, o crescimento das áreas de pastagens, desde meados da década de 1970, foi de apenas 4\% (DIAS-FILHO, 2014). O destacado aumento das áreas de pastagens no Norte do Brasil foi devido à evolução do efetivo bovino na região, o que de certa forma evidenciou o avanço do desmatamento da Floresta Amazônica.

Nas regiões Nordeste, Sudeste e Sul, a evolução do efetivo de bovinos praticamente se manteve constante de 1974 a 2014 (Figura 2). Na região do CentroOeste, houve um avanço de 311\% nesse período e no ano de 1981 o efetivo bovino do Centro-Oeste ultrapassou a quantidade de bovinos da região Sudeste. Outra importante região que vem se destacando com a criação de bovinos é a Norte, que apresentou a evolução do efetivo bovino de 1974 a 2014 em cerca de $2.000 \%$, sendo a evolução média de 1.093 .000 animais por ano.

DIAS-FILHO (2014) destacou baixo o crescimento médio das áreas de pastagem brasileiras nos últimos 30 anos, decorrente da expansão de áreas agrícolas, do reflorestamento e de urbanização sobre as áreas originais de pastagens. Pela diminuição das áreas de pastagens e o crescimento do efetivo de bovinos em todas grandes regiões brasileiras, houve o aumento da taxa de lotação, estimado em torno de $90 \%$. Nas regiões Norte e Centro-Oeste, a evolução da taxa de lotação das pastagens foi superior a $200 \%$. Isso demonstra, de certa forma, a intensificação da pecuária bovina.

Os avanços de tecnologias foram gradativamente transformando a pecuária brasileira. A partir do melhoramento genético animal, das pastagens cultivadas e adaptadas às condições geoclimáticas locais, além de medicamentos e defensivos agrícolas, pôde-se obter os incrementos da produção de bovinos. Entretanto, o desenvolvimento e o crescimento da produtividade ainda estão longe de atingir o limite, prova disso são os indicadores que colocam o Brasil em posição de produção extensiva e de fornecedor de produto de baixa qualidade (DIAS FILHO, 2011).

A crescente valorização das terras nas regiões do Brasil com maior história de ocupação, como a região Sudeste, foi impulsionada pela expansão dos mercados de cana-de-açúcar e pela produção de grãos, principalmente de milho e soja (GUANZIROLI, 2006; OLIVETTE et al., 2010). Com isso, tem-se a consequência do deslocamento da pecuária bovina para as regiões de fronteira agrícola do país, como as regiões Norte, Nordeste e Centro-Oeste, em que a terra é relativamente mais barata.

\section{A EVOLUÇAO DO EFETIVO BOVINO NO CENTRO-OESTE}

Os dados do efetivo rebanho bovino da região Centro-Oeste demonstram os registros de maior crescimento (Figura 3). No Brasil central, a pecuária sempre teve vantagens sobre os outros produtos, visto que devido à dificuldade de escoamento da produção para os grandes centros urbanos, o gado era o único produto que poderia deslocar de uma região para outra independentemente das condições de infraestrutura. As terras e a extensão do Centro-Oeste brasileiro eram ideais para o ENCICLOPÉDIA BIOSFERA, Centro Científico Conhecer - Goiânia, v.13 n.23; p. 615 2016 
meio de produção extensivo, dispensando maior volume de mão de obra e havia compatibilidade para os tipos de propriedades (ESTEVAM, 2004).

A bovinocultura expandiu com a exploração mais intensificada do Mato Grosso do Sul e do Mato Grosso. BORGES (2001) citou que o desenvolvimento da bovinocultura, nos dois estados, foi resultado de medidas governamentais, como a abertura da estrada de ferro Itapura-Corumbá, prolongamento da Estrada de Ferro Noroeste do Brasil, como parte da incorporação de novas terras.

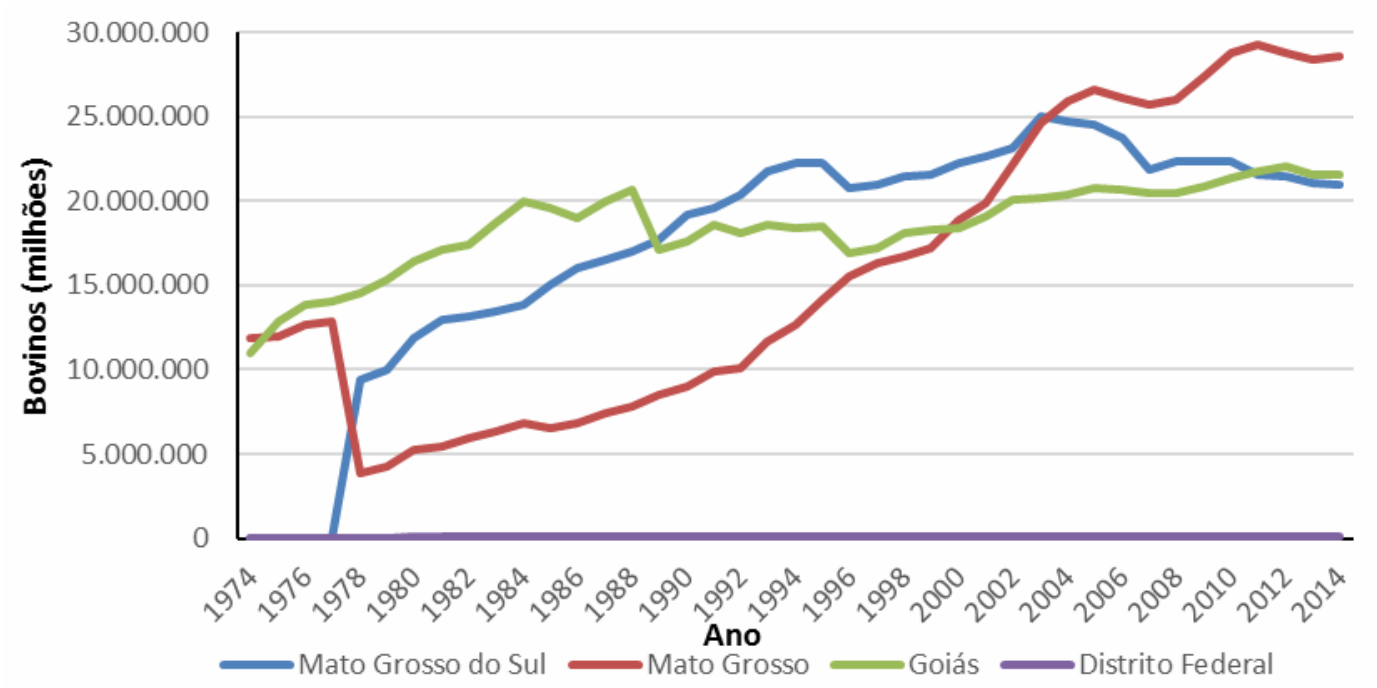

FIGURA 3. Evolução do efetivo bovino nos estados da região Centro-Oeste. Fonte: Adaptado IBGE (2014).

O gado curraleiro pé-duro, adaptou-se às regiões de clima quente e seco do Centro-Oeste, sendo, portanto, muito rústico e resistente. $O$ gado Pantaneiro desenvolveu-se no Pantanal do Mato Grosso e Mato-Grosso do Sul e foi decisivo para a ocupação das extensas áreas alagáveis dessa região. As raças Caracu, Canchim, Franqueiro, Gir, Girolando, Guzerá, Holandês, Junqueiro, Mocho Nacional, Nelore, Pantaneiro, Tabapuã são as raças envolvidas na modernização da pecuária do Centro-Oeste (SILVA et al., 2012).

Com a evolução do efetivo bovino no Centro-Oeste, desde o ano de 1981 ultrapassando a quantidade de bovinos do Sudeste, a grande região passou a ser o principal centro de criação de bovinos. Na abertura da região, o valor desbravador dos bovinos teve o destaque aliado às fazendas com grandes áreas. Outra característica importante deveu-se ao caráter inovador dos proprietários das grandes fazendas do Centro-Oeste, pois se baseavam em empreendimentos planejados com critérios modernos de administração. Constituindo, assim em empresas rurais organizadas, orientadas por técnicos especializados das áreas de ciências agrárias na exploração pecuária (SANTIAGO, 1970). Também, em 1977, com a divisão territorial e administrativa do antigo estado do Mato Grosso, dando origem ao estado de Mato Grosso do Sul, foi importante para o desenvolvimento regional e a evolução da bovinocultura. A construção da rodovia BR-163 foi importante para a formação de cidades em Mato Grosso, como Nova Mutum, Lucas do Rio Verde, Sorriso e Sinop, e para a expansão das áreas de criação de bovinos (MELO, 2009). 
O efetivo de bovinos na Região do Centro-Oeste obteve considerável aumento, a destacar o crescente aumento do rebanho nos estados de Mato Grosso e Mato Grosso do Sul, a partir da divisão dos dois estados. No ano de 1988, o rebanho bovino do estado do Mato Grosso do Sul ultrapassou o efetivo bovino de Goiás. O efetivo bovino de Mato Grosso ultrapassou o de Goiás em 2001 e o de Mato Grosso do Sul em 2005. A partir deste mesmo ano, o efetivo de bovinos do Mato Grosso do Sul começou a diminuir, ficando inferior ao de Goiás no ano de 2013 (Figura 4). Contribuiu para a queda do efetivo bovino no estado do Mato Grosso do Sul o surto de febre aftosa que ocorreu em 2005 e causou prejuízos econômicos (PILLONETTO, 2008) e, também, a ocupação de áreas pelas culturas alternativas, como a de soja e a de milho.

\section{A EVOLUÇÃO DO EFETIVO BOVINO EM GOIÁS}

No estado de Goiás, a bovinocultura esteve presente na economia desde a chegada dos primeiros habitantes, período em que a principal atividade produtiva brasileira era a extração de ouro (SILVA, 2011). A bovinocultura manteve-se viva como a principal atividade produtiva e econômica do estado de Goiás em quase todo - século XIX. Na primeira metade do século XX, chegaram as grandes transformações estruturais e econômicas em Goiás, decorrentes da mudança da capital do Estado para Goiânia em 1933, o que constituiu em intervenção direta do governo federal no sentido de alavancar o desenvolvimento do interior do país; e da mudança da capital federal para Brasília em 1960. Logo, junto com essas transformações, a pecuária se fortaleceu ainda mais, fazendo com que chegasse aos dias de hoje como um dos principais segmentos da economia do Estado (PAULA, 2011).

A evolução do efetivo bovino nas mesorregiões do Estado de Goiás é superior na mesorregião Sul Goiano, seguido pelo Noroeste Goiano, com pequena superioridade em relação ao Centro Goiano, e pelas mesorregiões Norte Goiano e Leste Goiano com a menor quantidade de animais (Figura 4). 


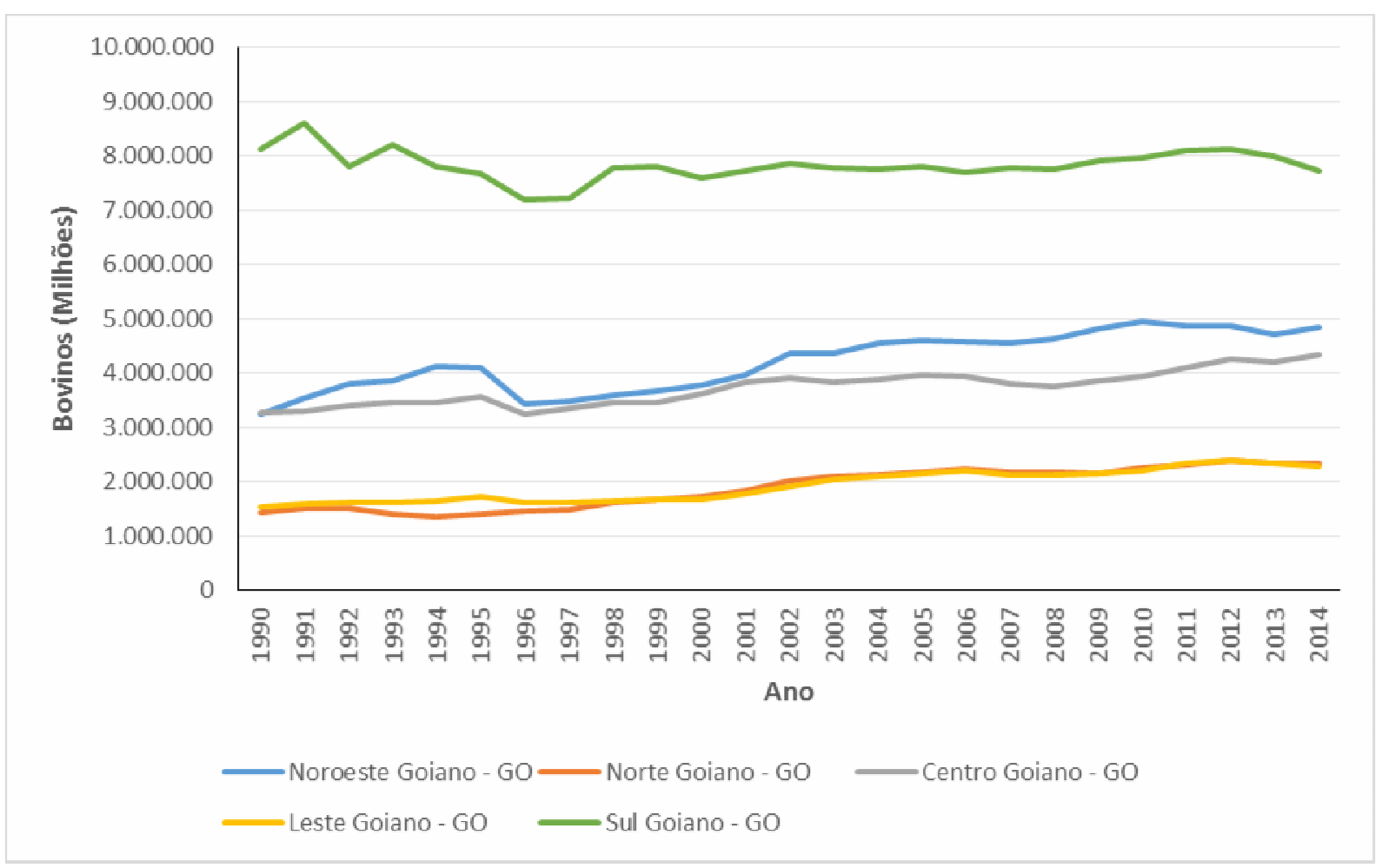

FIGURA 4. Evolução do efetivo bovino nas mesorregiões do Estado de Goiás. Fonte: Adaptado IBGE (2014).

No Estado de Goiás, a bovinocultura se instalou primeiro na região Norte Goiano. Só mais tarde, com a chegada do progresso junto com a estrada de ferro, vindos de São Paulo e Minas Gerais é que a região Sul Goiano se desenvolveu, tirando do norte a exclusividade do comércio de gado (GALLI, 2005). Fator importante na difusão da bovinocultura no estado de Goiás foi o cultivo das lavouras temporárias a partir de 1960, pois as áreas cultivadas com grãos em três anos de exploração eram transformadas em pastagens (SILVA, 2007). Pode-se destacar também, que em Goiás, as raças mais difundidas de forma absoluta são do grupo genético Bos taurus indicus, como os bovinos Gir, Guzerá e Nelore, formando a maioria do rebanho existente no estado.

O maior rebanho do estado desde tempos antigos encontra-se na mesorregião Sul Goiano. Inicialmente, a produção desta região estava diretamente ligada ao mercado do sudeste do país. Os goianos buscavam as matrizes e os reprodutores de raça apurada no Triângulo Mineiro, para o melhoramento genético de seus rebanhos (PAULA, 2011). Além dessa parceria comercial, era pelas cidades mineiras de Araguari e Uberaba, interligadas pela estrada de ferro ao grande centro paulista, que os goianos de toda extensão do sul, sudeste e sudoeste goiano, exportavam os produtos da pecuária bovina (ESTEVAM, 2004).

Para a economia, as regiões Norte e Leste de Goiás não tiveram a mesma oportunidade, visto terem a localização isolada comercialmente do resto do país. Assim, não tinham como melhorar o plantel bovino, continuavam com o rebanho nativo de baixa qualidade e de pouco valor comercial. A maioria das fazendas continuava organizada de forma tradicional. As fazendas não tinham divisões de pastos e o gado era criado extensivamente (BORGES, 2000). 
$\mathrm{Na}$ análise do efetivo bovino do estado de Goiás pelas microrregiões, observa-se a superioridade da quantidade de bovinos do Sudoeste de Goiás (Figura 5), confirmando que a localização estratégica influencia. O auge do efetivo bovino do Sudoeste de Goiás foi em 1991, com 3.260.766 milhões de cabeças, havendo decréscimo nos anos seguintes. A partir de 2000, nas microrregiões de São Miguel do Araguaia e Porangatu, houve importante desenvolvimento do efetivo bovino, explicado pela perda de áreas de pastagens para o cultivo de soja e milho na microrregião Sudoeste Goiano e pela intensificação da exploração nas microrregiões de São Miguel do Araguaia e Porangatu com a criação de bovinos.

O decréscimo do efetivo bovino da microrregião Sudoeste de Goiás, a partir de 1991, se deu pela retração da criação de bovinos nos municípios que historicamente tiveram os maiores rebanhos, Rio Verde e Jataí (Figura 6). Nas duas cidades, as culturas alternativas, principalmente de soja e milho, vêm tomando os espaços das pastagens. O município de Caiapônia, desde o ano de 2003, tem o maior rebanho da microrregião Sudoeste de Goiás, seguido a partir de 2013 pelo rebanho do município de Mineiros.

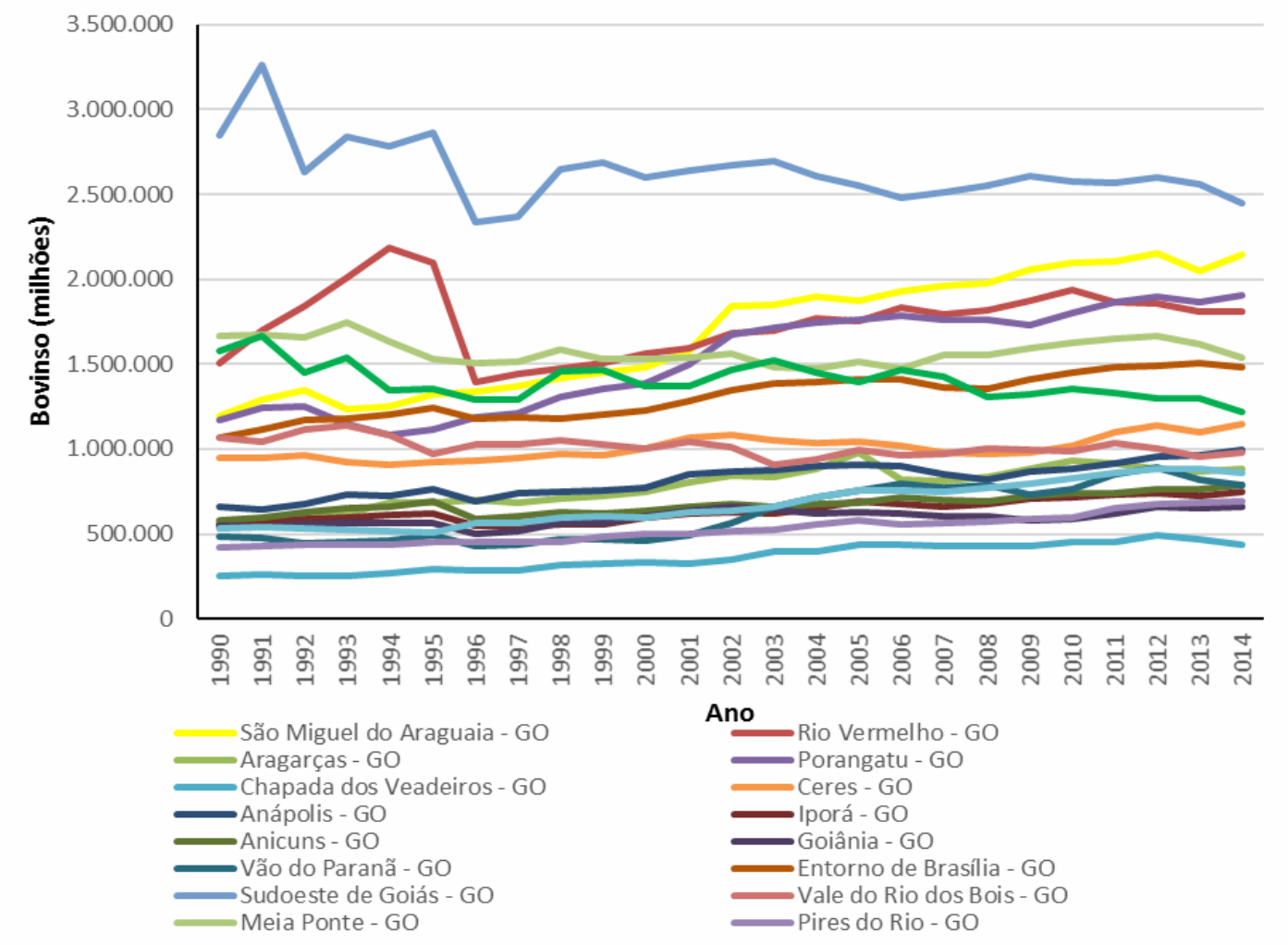

FIGURA 5. Evolução do efetivo bovino nas microrregiões do Estado de Goiás. Fonte: Adaptado IBGE (2014). 


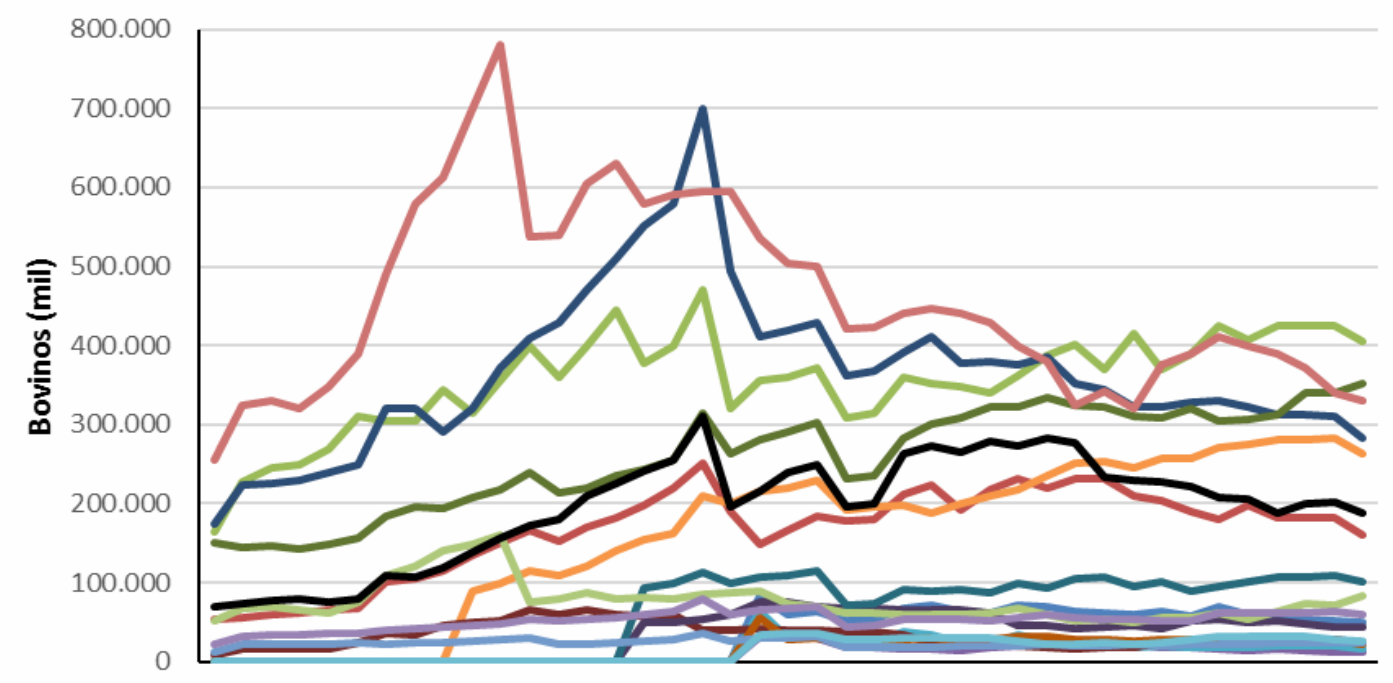

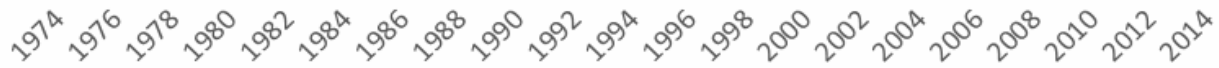

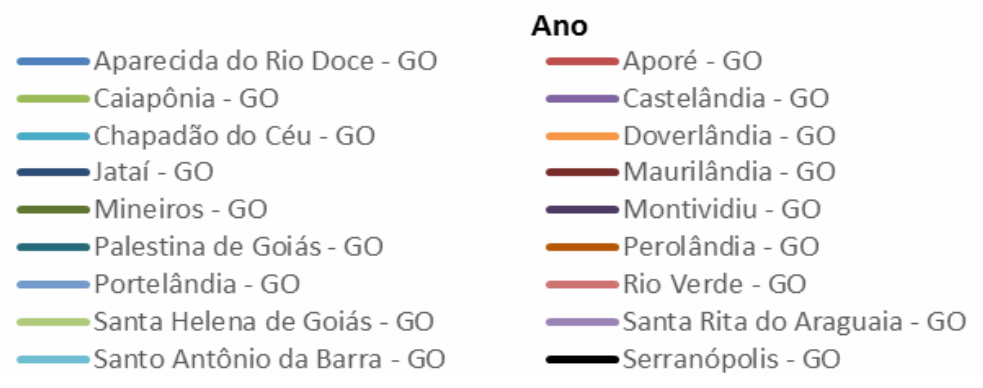

FIGURA 6. Evolução do efetivo bovino nos municípios da microrregião Sudoeste de Goiás. Fonte: Adaptado IBGE (2014).

\section{A EVOLUÇÃO DO EFETIVO BOVINO EM JATAÍ, GO}

O município de Jataí teve seu maior rebanho bovino em 1991, totalizando 700 mil animais (Figura 7). A partir desta data houve decréscimo acentuado do efetivo bovino. No ano de 2014, tem-se o registro de 283 mil bovinos. Isso ocorreu devido ao crescimento da área plantada pelas culturas alternativas, como a cultura de soja, que desde o ano de 1996 está aumentando, passando de 91.768 para 278 mil hectares de soja plantada em 2014 (IBGE, 2014). 


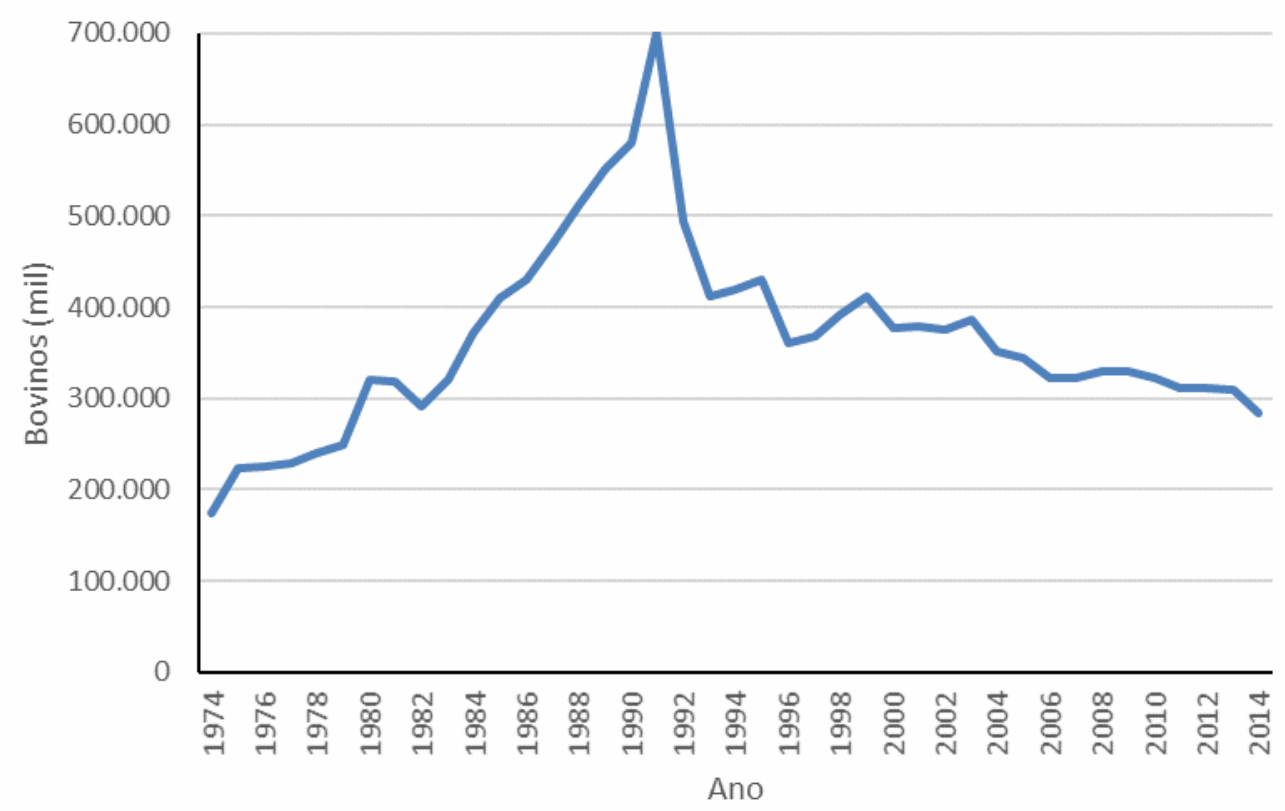

FIGURA 7. Evolução do efetivo bovino no município de Jataí, GO. Fonte: Adaptado IBGE (2014).

\section{CONCLUSÕES}

Com a interiorização do rebanho brasileiro, dos primórdios da chegada dos bovinos no Brasil aos dias atuais, é percebida que a atividade pecuária tem seu desenvolvimento vinculado a intensificação de aproveitamento do território, à ocupação do interior e das regiões de melhor adaptação aos bovinos. A evolução do efetivo bovino é significativa nas regiões Norte e Centro-Oeste do Brasil, com destaque ao estado do Mato Grosso. Enquanto que nas regiões Nordeste, Sudeste e Sul, o efetivo bovino vem se estabilizando.

A migração da pecuária decorre da implantação de culturas alternativas, como a soja, o milho e a cana no cerrado brasileiro. De certa forma, tal situação exerce a pressão sobre a atividade, em contrapartida contribui para o avanço da mesma, o que resulta em melhor eficiência produtiva e melhor acabamento de carcaças evolutivamente para garantir a renda. O início da suplementação mineral protéica nos anos 80 foi o marco primordial para a produtividade do país.

O município de Jataí, GO, acompanha a evolução brasileira, sendo destaque na produção de grãos e com o efetivo bovino oscilando, exigindo as adaptações para a eficiência em produtividade.

\section{REFERÊNCIAS}

ABIEC - ASSOCIAÇÃO BRASILEIRA DAS INDÚSTRIAS EXPORTADORAS DE CARNE. Rebanho Bovino Brasileiro. 2011. Disponível em: <http://www.abiec.com.br/3_pecuaria.asp>. Acesso em: 07 de janeiro de 2016.

ABIEC - ASSOCIAÇÃO BRASILEIRA DAS INDÚSTRIAS EXPORTADORAS DE CARNE. Balanço da pecuária. 2014. Disponível em:< http://www.abiec.com.br/texto.asp?id=8>. Acesso em: 04 de janeiro de 2016. 
ARAUJO, T.P; VIANNA, S.T.W; MACAMBIRA, J. Cinquenta anos de formação econômica do Brasil: ensaios sobre a obra de Celso Furtado. Rio de Janeiro: IPEA, 2009. 288p.

BORGES, B.G. Goiás nos Quadros da Economia Nacional 1930 - 1960. Goiânia: UCG, p.172, 2000.

BORGES, F.T.M. Do extrativismo à Pecuária: algumas observações sobre a história econômica do Mato Grosso (1870-1930). São Paulo: Scortecci, 2001.

CARVALHO, T.B.; ZEN, S.; TAVARES, E.C.N. Comparação de custo de produção na atividade de pecuária de engorda nos principais países produtores de carne bovina. In: CONGRESSO DA SOCIEDADE BRASILEIRA DE ECONOMIA, ADMINISTRAÇÃO E SOCIOLOGIA RURAL, 47. 2009, Porto Alegre. Anais... Porto Alegre: $\quad$ SOBER, $2009 . \quad$ Disponível em: <http://www.sober.org.br/palestra/13/356.pdf>. Acesso em: 04 de janeiro de 2016.

CRPBZ - CENTRO DE REFERENCIA DA PECUARIA BRASILEIRA - ZEBU. Uma breve história sobre a introdução do Zebu no Brasil. 2015a. Disponível em: $<$ http://www.crpbz.org.br/Home/Conteudo/13442-Uma-breve-historia-sobre-aintroducao-do-Zebu-no-Brasil>. Acesso em: 02 de janeiro de 2016.

CRPBZ - CENTRO DE REFERENCIA DA PECUARIA BRASILEIRA - ZEBU. Uma Breve Apresentação sobre as Importações (1a Fase). 2015b. Disponível em: $<$ http://www.crpbz.org.br/Home/Conteudo/14105-Uma-Breve-Apresentacao-sobreas-Importacoes-(1a-Fase)>. Acesso em: 02 de janeiro de 2016.

CRPBZ - CENTRO DE REFERENCIA DA PECUARIA BRASILEIRA - ZEBU. Uma Breve Apresentação sobre as Importações (2 Fase). 2015c. Disponível em: $<$ http://www.crpbz.org.br/Home/Conteudo/14116-Uma-Breve-Apresentacao-sobreas-Importacoes-(2a-Fase) >. Acesso em: 02 de janeiro de 2016.

CRPBZ - CENTRO DE REFERENCIA DA PECUARIA BRASILEIRA - ZEBU. Terceira Fase (1898 - 1921). 2015d. Disponível em: <http://www.crpbz.org.br/Home/Secao/9607-Terceira-Fase-(1898-1921)>. Acesso em: 02 de janeiro de 2016.

CRPBZ - CENTRO DE REFERENCIA DA PECUARIA BRASILEIRA - ZEBU. Quarta Fase (1930 - 1960). 2015e. Disponível em: <http://www.crpbz.org.br/Home/Secao/9608-Quarta-Fase-(1930-1960)>. Acesso em: 02 de janeiro de 2016.

CRPBZ - CENTRO DE REFERENCIA DA PECUARIA BRASILEIRA - ZEBU. Quinta Fase (1994 - 2010$)$ 2015f. Disponível em: <http://www.crpbz.org.br/Home/Secao/9609-Quinta-Fase-(1994-2010)>. Acesso em: 02 de janeiro de 2016.

DIAS-FILHO, M.B. Os desafios da produção animal em pastagens na fronteira agrícola brasileira. Revista Brasileira de Zootecnia, v.40, supl. Especial, p.270- 
279, 2011. Disponível em: <http://www.sbz.org.br/revista/artigos/66282.pdf>. Acesso em: 28 de janeiro de 2016.

DIAS-FILHO, M.B. Diagnóstico das pastagens no Brasil. Belém, PA: Embrapa Amazônia. Documento ISSN 1983-0513 n.402. 2014. Disponível em: <http://ainfo.cnptia.embrapa.br/digital/bitstream/item/102203/1/DOC-402.pdf>.

Acesso em: 10 de janeiro de 2016.

ESTEVAM, L.O. Tempo da Transformação. Estrutura e dinâmica da formação econômica de Goiás. 2ª edição. Goiânia: UCG, p.238, 2004.

EUCLIDES FILHO, K.; EUCLIDES, V.P.B. Desenvolvimento recente da pecuária de corte brasileira e suas perspectivas. In: PIRES, A.V. Bovinocultura de Corte. Piracibaba: FEALQ, v.1, p.11-41, 2010.

GALLI, U. A História da Pecuária em Goiás. Do primeiro gado aos dias de hoje. Goiânia: UCG, p.100, 2005.

GUANZIROLI, C.E. Agronegócio no Brasil: perspectivas e limitações. 2006. Universidade Federal Fluminense Faculdade de Economia. Disponível em: $<$ http://www.uff.br/econ/download/tds/UFF_TD186.pdf>. Acesso em: 26 de fevereiro de 2016.

IBGE - INSTITUÍDO BRASILEIRO DE GEOGRAFIA E ESTATÍSTICAS. Sistema IBGE de recuperação automática SIDRA. Pesquisa Pecuária Municipal. 2014. Disponível em: $<$ http://www.sidra.ibge.gov.br/bda/tabela/listabl.asp?c=1092\&z=t\&o=24>. Acesso em: 5 de dezembro de 2015.

MELO, J.S. Qual é o determinante da expansão da fronteira agrícola Matogrossense no período 2001/2007: agrícola ou pecuária? 2009. Dissertação (Mestrado em Agronegócios e Desenvolvimento Regional), Faculdade de Economia, Universidade Federal de Mato Grosso, Cuiabá, 2009. Disponível em: <http://www.ufmt.br/ufmt/site/userfiles/file/adr/Disserta\%C3\%A7\%C3\%B5es/Disserta \%C3\%A7\%C3\%A30 Jos\%C3\%A9Silveira(1).pdf >. Acesso em: 10 de janeiro de 2016.

MEZZADRI, F.P. PECUÁRIA DE CORTE. DERAL - Departamento de Economia Rural. SEAB - Secretaria de Estado da Agricultura e do Abastecimento. p.1-14. Disponível em: $<$ http://www.agricultura.pr.gov.br/arquivos/File/deral/Prognosticos/pecuaria_corte_13 _14.pdf > Acessado em: 6 de janeiro de 2016.

MONZATTO, C.V.; FREITAS JUNIOR, E.; PERES, J.R.R. Uso Agrícola dos Solos Brasileiros. Rio de Janeiro: Embrapa Solos. 2002. 174p.

OLIVETTE, M.P.A.; NACHILUK, K.; FRANCISCO, V.L.F.S. Análise comparativa da área plantada com cana-de-açúcar frente aos principais grupos de culturas nos municípios paulistas, 1996-2008. Informações Econômicas, v.40, n.2, p.42-59, 2010. 
PAULA, J.L. Pecuária Bovina de Corte em Goiás (1940-2009). 2011. Dissertação (Mestrado em Mestrado em Desenvolvimento e Planejamento Territorial) - Pontifícia Universidade Católica. Disponível em: <http://www.cicarne.com.br/wpcontent/uploads/2014/01/Cadeia-GO-1.pdf>. Acesso em: 10 de janeiro de 2016.

PEIXOTO, A.M. Evolução histórica da pecuária de corte no Brasil. In: PIRES, A.V. Bovinocultura de Corte. Piracicaba: FEALQ, v.1, p.3-10, 2010a.

PEIXOTO, A.M. Raças de bovinos de corte que interessam ao Brasil. In: PIRES, A.V. Bovinocultura de Corte. Piracicaba: FEALQ, v.1, p.55-73, 2010b.

PILLONETTO, E. Febre aftosa e relatos de Mato Grosso do Sul. 2008. Monografia (Especialização Lato sensu em Vigilância em Saúde e Defesa Sanitária Animal UCB) - Universidade Castelo Branco: Campo Grande. Disponível em: $<$ http://qualittas.com.br/uploads/documentos/Febre\%20Aftosa\%20e\%20Relatos\%20\%20Eucrecio\%20Pillonetto.PDF>. Acesso em: 10 de janeiro de 2016.

SANTIAGO, A.A. Pecuária no Brasil Central. São Paulo: Instituto de Zootecnia, Secretaria da Agricultura, 1970.

SANTIAGO, A.A. Os cruzamentos na pecuária bovina. São Paulo: Instituto de Zootecnia, São Paulo, SP, 1975. p.549.

SCOT, Consultoria. Cadeia produtiva da carne bovina. 2011. Disponível em: $<$ http://www.abiec.com.br/img/Upl/osetor-101012.pdf>. Acesso em: 30 de janeiro de 2016.

SILVA, E.R. A Economia Goiana no Contexto Nacional 1970-2000. Goiânia: UCG, p.215, 2007.

SILVA, G.F. Modernização Agropecuária e Turismo de Negócios em Goiás. 2011 Dissertação (Mestrado em Desenvolvimento e Planejamento Territorial - MDPT) Pontifícia Universidade Católica de Goiás: Goiânia. 2011. Disponível em: $<$ http://tede.biblioteca.ucg.br/tde busca/arquivo.php?codArquivo=859 >. Acesso em: 10 de janeiro de 2016.

SILVA, M.C.; BOAVENTURA, V.M.; FIORAVANTI, M.C.S. História do povoamento bovino no Brasil Central. Revista UFG, ano XIII, n.13, p.34-41, 2012. Disponível em: $<$ https://www.researchgate.net/profile/Marcelo Correa da Silva/publication/2678114 02 HISTORIA DO POVOAMENTO BOVINO NO BRASIL CENTRAL/links/545b0 97a0cf2c46f6643930d.pdf>. Acesso em: 20 de fevereiro de 2016. 